\title{
ANÁLISE DA TEMPERATURA E UMIDADE RELATIVA DO AR NO BAIRRO SANTA HELENA NA CIDADE DE OSVALDO CRUZ/SP
}

\author{
Carlos Roberto Caputo, Margarete Cristiane de Costa Trindade Amorim
}

Universidade Estadual Paulista - UNESP, Curso de Geografia, Presidente Prudente, SP. Fundação de Amparo à Pesquisa do Estado de São Paulo - FAPESP. E-mail: caarobert1@hotmail.com

\section{RESUMO}

A partir da expansão territorial urbana, o ambiente natural foi transformado havendo como consequências alterações nos elementos do clima, como a temperatura e umidade relativa do ar. Assim, o presente estudo teve como objetivo analisar o campo térmico e higrométrico do bairro Santa Helena em comparação ao ambiente rural próximo na cidade de Osvaldo Cruz/SP. Para isto, foram utilizados pontos fixos de coleta de dados desses dois elementos do clima, relacionando-os com o diferenciado uso e ocupação da terra e as características do relevo. Os resultados mostraram alterações na atmosfera local do Santa Helena, com registro de ilhas de calor e ilhas secas às $15 \mathrm{~h}$, com intensidades de até $+4,2 \circ \mathrm{C}$ e $-3,8 \%$, respectivamente. Entretanto, à Oh foram diagnosticadas ilhas de frescor e ilhas úmidas, com valores máximos de $-4,4$ ㅇ $\mathrm{C}$ $+21,9 \%$, respectivamente.

Palavras-chave: Temperatura, Umidade relativa, Uso e ocupação da terra, Santa Helena, Osvaldo Cruz/SP.

\section{ANALYSIS OF TEMPERATURE AND RELATIVE HUMIDITY OF AIR IN SANTA HELENA NEIGHBORHOOD IN THE CITY OF OSVALDO CRUZ/SP}

\begin{abstract}
From the urban territorial expansion, the natural environment was transformed resulting in changes in the elements of the climate, such as the temperature and relative humidity of the air. Thus, the present study aimed to analyze the thermal and hygrometric field in the Santa Helena neighborhood in comparison to the nearby rural environment in the city of Osvaldo Cruz/SP. For this, fixed points of data collection of these two elements of the climate were used, relating them with the different use and occupation of the land and the characteristics of the relief. The results showed changes in the local atmosphere of Santa Helena, with heat islands and dry islands recorded at $15 \mathrm{~h}$, with intensities of up to $+4,2 \circ \mathrm{C}$ and $-3,8 \%$ respectively. However, at $0 \mathrm{~h}$, fresh islands and wet island were diagnosed, with maximum values of $-4,4 \circ \mathrm{C}$ and $+21,9 \%$ respectively.

Keywords: Temperature, Relative humidity, Use and occupation, Santa Helena, Osvaldo Cruz/SP.
\end{abstract}

\section{INTRODUÇÃO}

No Brasil, o crescimento das cidades ocorreu de forma acelerada a partir da década de 1950 e segundo Ehlers (1999), o processo de modernização da agricultura foi o principal fator que elevou as taxas de êxodo rural no país, retirando as pessoas do campo e introduzindo-as nas cidades como mão de obra nas indústrias e nos serviços.

\begin{tabular}{lll}
\multicolumn{3}{c}{ A partir da expansão urbana, o ambiente } \\
natural foi transformado. Para o \\
desenvolvimento das cidades, a sociedade
\end{tabular}

introduziu materiais que acarretam na ocupação diferenciada do solo urbano.

Dentre tantos problemas presentes nos ambientes urbanos, destacam-se a retirada da cobertura arbórea, a impermeabilização generalizada do solo e as mudanças no relevo, que ocasionam enchentes nos períodos chuvosos, a poluição dos rios pela falta de saneamento básico, o aumento da poluição do ar através da queima de combustíveis fósseis, além do próprio aquecimento da atmosfera local.

Assim, as cidades apresentam características únicas, distintas do ambiente 
rural. Como traço marcante do ambiente urbano, destacam-se as diferenças térmicas ocasionadas pela maior concentração de edificações com os mais diversos materiais construtivos. As propriedades radioativas destes materiais interferem no balanço energético, armazenando mais calor nestas áreas, desenvolvendo o fenômeno das ilhas de calor.

As ilhas de calor originam-se através da diferenciada capacidade de absorção de energia dos materiais encontrados na superfície urbana em relação ao ambiente rural (AMORIM et al., 2009).

Diante disto, buscou-se na cidade de Osvaldo Cruz (Figura 1), considerada de pequeno porte, com 30.917 habitantes (IBGE, 2010) ${ }^{1}$, comparar as características da temperatura e umidade relativa do ar entre o rural e o bairro Santa Helena, considerado de baixa qualidade ambiental, segundo Lima (2007).

\footnotetext{
${ }^{1}$ Instituto Brasileiro de Geografia e Estatística. Disponível em: < https://cidades.ibge.gov.br/brasil/sp/osvaldo-cruz/panorama>. Acesso em: 30 jul. 2018.
} 
Figura 1. Mapa de localização de Osvaldo Cruz/SP

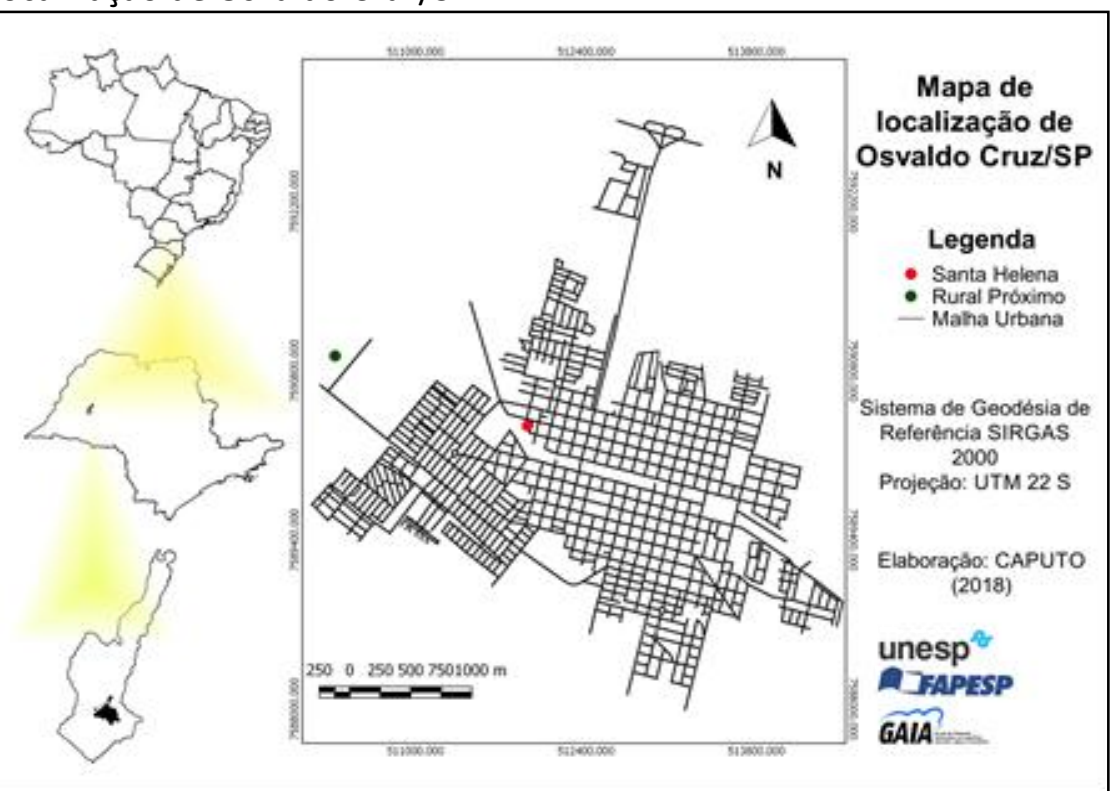

Fonte: Autoria própria.

Portanto, o presente estudo teve como objetivo analisar o campo térmico e higrométrico do bairro Santa Helena em comparação ao ambiente rural próximo na cidade de Osvaldo Cruz/SP, em horário representativo do maior aquecimento diurno (15h) e no período noturno (Oh).

\section{METODOLOGIA}

Esta pesquisa possui como aporte teórico-metodológico as concepções desenvolvidas por Monteiro (1976) em que os estudos sobre clima urbano devem adotar um viés integrador, considerando a junção entre o homem e a natureza através do espaço modificado, intitulado como Sistema Clima Urbano (S.C.U.).

Esta perspectiva sistêmica e integradora definiu o clima urbano como "um sistema que abrange o clima de um dado espaço terrestre e sua urbanização" (MONTEIRO, 1976, p. 116). Para os estudos do S.C.U., o autor adotou três canais de percepção humana, sendo eles o termodinâmico (conforto térmico), o físicoquímico (qualidade do ar) e o hidrometeórico (impactos meteóricos).

Assim, com base no referido autor, esta pesquisa se enquadra nos estudos do subsistema termodinâmico, relacionando-se com o conforto térmico, no qual são tratadas as ilhas de calor/frescor e as ilhas secas/úmidas.

Como forma de compreender o uso e a ocupação do solo no ambiente urbano de Osvaldo Cruz, utilizou-se da Carta de Qualidade
Ambiental desenvolvida por Lima (2007). A autora constatou que alguns bairros apresentaram alta qualidade ambiental, enquanto que outros foram considerados de baixa qualidade ambiental. Os atributos utilizados pela mesma, para se chegar nessa diferenciação foram os seguintes: o uso do solo; cobertura vegetal arbórea; áreas de risco de enchentes; alta densidade populacional e déficit de espaços públicos destinados a áreas verdes.

Deste modo, escolheu-se o bairro Santa Helena, Figura 2, para a instalação de sensores de temperatura e umidade relativa do ar. Este bairro foi caracterizado como de baixa qualidade ambiental (LIMA, 2007) e apresentou usos e ocupações do solo distintos se comparado ao rural próximo (Figura 3). Tal bairro possui pequenos lotes, predominância de telhados de fibrocimento e ausência de vegetação.

Figura 2. Características predominantes do solo no bairro Santa Helena

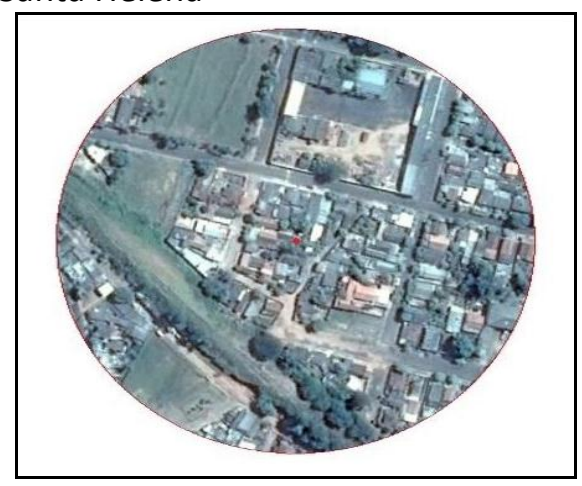

Fonte: Google Earth (2010). 
Já o ambiente rural próximo, apresentou o predomínio de pastagens e plantações de café, além de esparsas áreas com vegetação arbórea e pouca densidade construtiva.

Figura 3. Características predominantes do solo no rural próximo

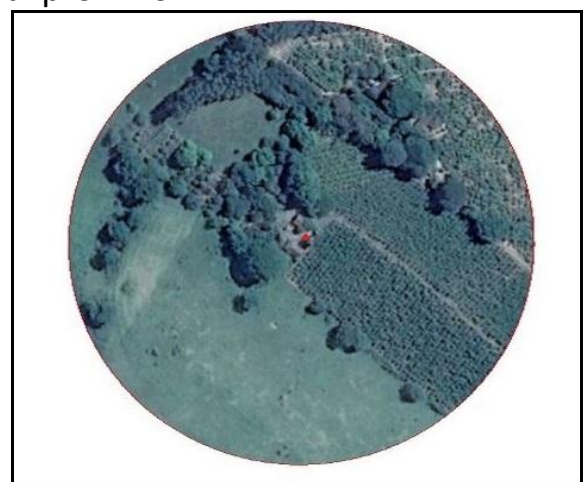

Fonte: Google Earth (2010).

A coleta dos dados de temperatura e umidade relativa ocorreram durante o mês de setembro de 2017, através das miniestações meteorológicas digitais do tipo "Humiditytemperate logger", da marca "Thermo Data ${ }^{\mathrm{TM}}$ e neste artigo, utilizou-se os dados referentes às $15 \mathrm{~h}$ e Oh, buscando compreender como se apresentou a atmosfera local durante diferentes períodos do dia.

A partir das fórmulas $(\Delta T=u-r)$ e $(\Delta U R=$ $u-r)$, foram calculadas as intensidades dos dados térmicos e higrométricos, buscando as diferenças dos elementos do clima entre o ambiente urbano e rural próximo. Os resultados dos cálculos estatísticos das intensidades foram organizados em gráficos no aplicativo Excel ${ }^{\circledR 2}$.

\section{RESULTADOS}

A partir da Figura 4, é possível notar que o bairro Santa Helena apresentou às 15h, temperaturas mais elevadas se comparado ao ambiente rural. Neste período, os maiores registros de ilhas de calor foram nos dias 03 e 20 , com intensidades de $+3,8 \circ \mathrm{C}$ e $+4,2^{\circ} \mathrm{C}$ respectivamente, configurando episódios de ilhas de calor de média e forte magnitudes, segundo a classificação elaborada por Fernández García (1996). Já no período noturno, à Oh, o bairro apresentou ilhas de frescor com intensidades significativas, com valores de $-4,4$ 으 $\mathrm{e}-3,4^{\circ} \mathrm{C}$ nos dias 05 e 08.

\footnotetext{
${ }^{2}$ Excel $^{\circledR}$ é a marca registrada da Microsoft Corporation.
} 
Figura 4. Intensidades da temperatura do ar no bairro Santa Helena às $15 \mathrm{~h}$ e $0 \mathrm{~h}$

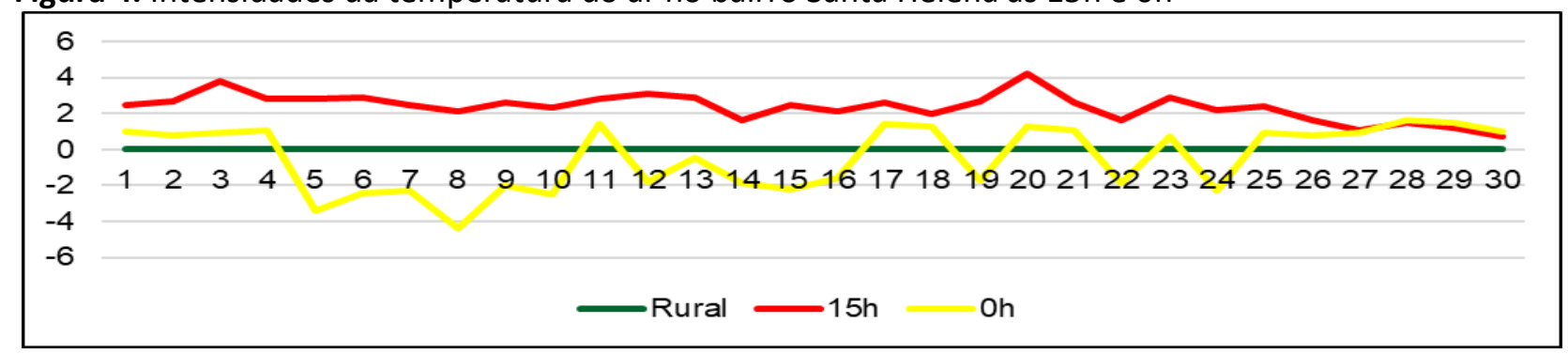

Fonte: Autoria própria.

Referente à umidade relativa do ar (Figura 5), é possível observar elevadas intensidades de ilhas úmidas nos dias 05 e 08, com valores de $+15,4 \%$ e $+21,9 \%$ respectivamente à 0 h. Já no período diurno, a umidade do bairro permaneceu menor que a registrada no ambiente rural durante todo o mês de setembro de 2017, havendo a formação de ilhas secas com intensidades de $-3,7 \%$ no dia 01 e $-3,8 \%$ no dia 28 .

Figura 5. Intensidades da umidade relativa do ar no bairro Santa Helena às $15 \mathrm{~h}$ e $0 \mathrm{~h}$

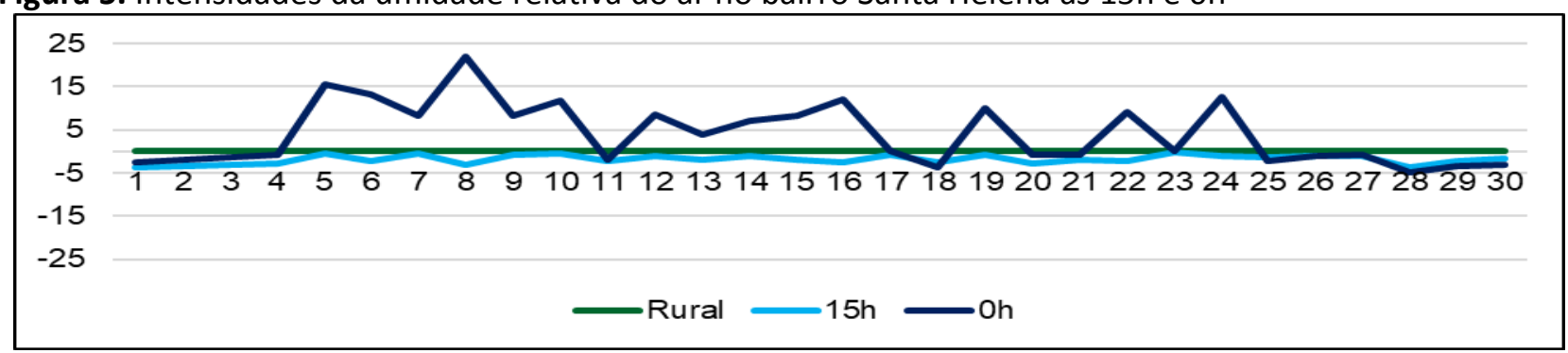

Fonte: Autoria própria.

\section{DISCUSSÕES}

Considerado como importante influenciador do clima urbano, os diferentes usos e ocupações do solo impactam diretamente na composição física da atmosfera, modificando a temperatura e a umidade relativa do ar.

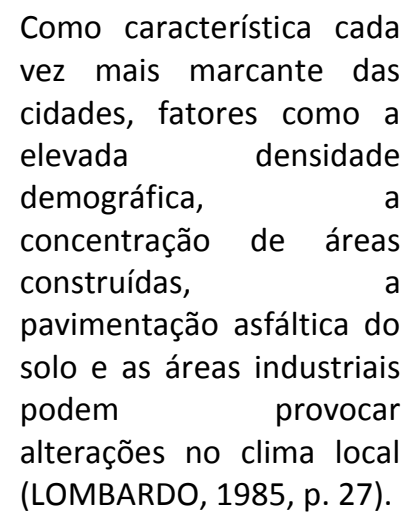

Deste modo, o uso e ocupação do solo, presentes no bairro Santa Helena acarretou em importantes alterações na atmosfera local, fazendo com que os elementos do clima se apresentassem de forma diferenciada nos resultados encontrados no ambiente rural próximo.
No horário diurno, às $15 \mathrm{~h}$, em dias sem precipitação (INMET) ${ }^{3}$ influenciados pelos sistemas atmosféricos estáveis, como a Massa Tropical Atlântica e Massa Tropical Atlântica Continentalizada (INPE) ${ }^{4}$, com ventos de Leste e Sudeste, formaram-se ilhas de calor de média e forte magnitudes. Isto se deve ao fato de que o bairro, ao situar-se próximo à área central, recebeu o ar quente e seco proveniente do setor Leste da cidade, contribuindo para os valores registrados. Além disto, por apresentar falta de vegetação arbórea e predominância de telhados de fibrocimento, a atmosfera local aqueceu durante o dia, resultando em elevadas intensidades de ilhas de calor e ilhas secas.

Já à Oh, o relevo exerceu grande influência nos resultados térmicos e higrométricos devido ao fundo de vale localizado à nordeste do bairro (Figura 6).

\footnotetext{
${ }^{3}$ Instituto Nacional de Meteorologia. Disponível em: <http://www.inmet.gov.br/portal/>. Acesso em: 30 jul. 2018.

${ }^{4}$ Instituto Nacional de Pesquisas Espaciais. Disponível em: <http://www.inpe.br/>. Acesso em: 30 jul. 2018.
} 
Figura 6. Mapa Hipsométrico de Osvaldo Cruz/SP

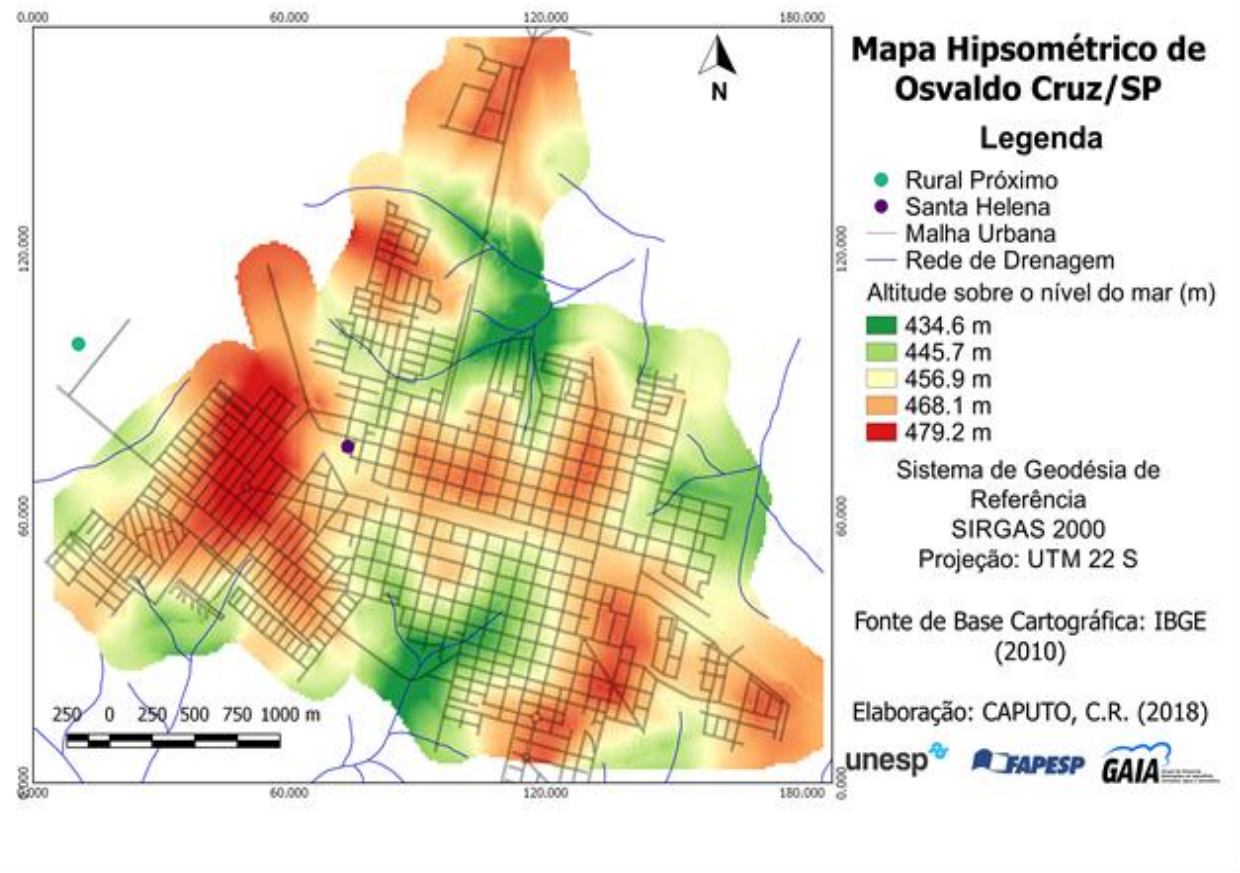

Fonte: Autoria própria.

Conforme a Figura 6, ao receber ventos de Nordeste originados de sistemas atmosféricos estáveis, o ar mais frio e úmido do entorno rural foi canalizado no fundo de vale e transportado para o bairro localizado no centro da cidade, resultando na diminuição da temperatura e o aumento da umidade relativa do ar.

\section{CONCLUSÃO}

Como resultados desta pesquisa, por meio dos dados de temperatura e umidade relativa, foi possível compreender como o bairro Santa Helena reuniu condições para desenvolver seu próprio clima através do uso e ocupação diferenciado do solo e influenciado pelo relevo próximo.

Notou-se um padrão de aquecimento no período diurno. Este resultado deve-se às condições de uso e ocupação do solo, que ao possuir telhados de fibrocimento, mais baratos economicamente, o bairro Santa Helena aqueceu rapidamente, resultando na formação de ilhas de calor e ilhas secas.

Já no período noturno, com ventos provenientes de Nordeste, o bairro recebeu o ar mais frio do entorno rural canalizado pelo fundo de vale, o que resultou na formação de ilhas de frescor e ilhas úmidas.

Assim, este estudo mostrou que a população residente no bairro estudado se encontra suscetíveis às intempéries climáticas, já que foram registrados dias com intensidades de $+4,2 \circ \mathrm{C}$ e noites com $-4,4$ 으.

Segundo Ayoade (1986), grandes variações térmicas e higrométricas podem desencadear problemas à saúde humana, como processos inflamatórios e doenças contagiosas.

Deste modo, como forma de amenizar esta oscilação de temperatura, há a opção de pintura dos telhados de fibrocimento com tintas de coloração branca. Segundo Silveira; Marinoski; Lambers (2012), a pintura dos telhados resultará no aumento do albedo, havendo como consequência a diminuição da temperatura no local e a diminuição da amplitude térmica.

Além disto, mostra-se fundamental o plantio de vegetação arbórea nas calçadas e nos fundos dos quintais, visando a diminuição da temperatura local através do processo de evapotranspiração, aumentando o calor latente e diminuindo o calor sensível (AMORIM, 2017), contribuindo para a qualidade de vida da população.

\section{REFERÊNCIAS}

AMORIM, M. C. C. T. et al. (Orgs.), Características da ilha de calor em cidades de porte médio: exemplos de Presidente Prudente (Brasil) e Rennes (França). Confins, v. 7, p. 1-16, 2009. Disponível 
<http://confins.revues.org/index6070.html>. Acesso em: 01 ago. 2018.

AMORIM, M. C. C. T. Teoria e método para o estudo das ilhas de calor em cidades tropicais de pequeno e médio porte. 2017. 178 f. Tese (Livre Docente em Climatologia Geográfica) Universidade Estadual Paulista, Presidente Prudente, 2017.

AYOADE, J. O. Introdução à climatologia para os trópicos. São Paulo: Difle, 1986.

EHLERS, E. Agricultura sustentável: origens e perspectivas de um novo paradigma. 2. ed. Guaíba: Agropecuária, 1999.

FERNÁNDEZ GARCÍA, F. Manual de climatologia aplicada: clima, médio ambiente y planificación. Madrid: Editorial Síntesis, S.A., 1996, p. 264.

LIMA, V. Análise da qualidade ambiental na cidade de Osvaldo Cruz/SP. 2007. $146 \mathrm{f}$. Dissertação (Mestrado em Geografia) Universidade Estadual Paulista, Faculdade de Ciências e Tecnologia, Presidente Prudente.

LOMBARDO, M. A. Ilha de calor nas metrópoles: o exemplo de São Paulo. São Paulo: Hucitec, 1985 , p. 27.

MONTEIRO, C. A. F. Teoria e clima urbano. São Paulo: Universidade de São Paulo/Instituto de Geografia, 1976. 181 f. (Série Teses e Monografias, 25), p. 116.

SANTOS, M. A evolução recente da população urbana, agrícola e rural. In: (Org.). A urbanização brasileira. 5. ed. São Paulo: Edusp, 2008.

SILVEIRA, R.; MARINOSKI, D. L.; LAMBERTS, R. Avaliação da absortância à radiação solar e temperatura superficial de telhas de fibrocimento utilizadas nas coberturas de edificações do campus da UFSC. In: XIV ENTAC - Encontro Nacional de Tecnologia do Ambiente Construído 14, 2012, Juiz de Fora. Anais... Juiz de Fora, 2012, p. $1166-1170$.
Recebido para publicação em 08/08/2018

Revisado em 03/09/2018

Aceito em 06/09/2018 